\section{The use of high dose lormetazepam in psychiatric in-patients}

M. Ansseau, M.D.,

A. F. Dawson," M.B., Ch.B., and

F. Champion, ** M.D.

Unité de Psychopharmacologie,

Hôpital Universitaire de

Bavière, Liège, Belgium,

*Research and Development

Division, Wyeth Europa Ltd.,

Taplow, England, and

**Wyeth S.A., Brussels, Belgium

Curr. Med. Res. Opin., (1982), 7, 598.

Received: 6th October 1981

\title{
Summary
}

An open study was carried out in 19 severely disturbed psychiatric in-patients to assess the effectiveness of lormetazepam in improving particularly resistant insomnia. Patients were given single doses of lormetazepam up to $6 \mathrm{mg}$ nightly, i.e. 3-times the maximum recommended daily dose, over a mean period of 30 days. Subjective response to treatment was assessed as 'good' in 18 and as 'fair' in the remaining patient. No adverse effects or drug interactions with a wide variety of psycho-active drugs given concomitantly were noted. Mild 'hang-over' effects only were reported in 5 patients.

Key words: Lormetazepam - benzodiazepine tranquillizers - sleep disorders

\section{Introduction}

Lormetazepam is a new 1,4 benzodiazepine which has undergone extensive clinical evaluation throughout Europe. Following oral administration, lormetazepam has been shown to be rapidly absorbed, therapeutic levels being achieved within half an hour. ${ }^{2}$ The plasma concentration is observed to decrease in two phases: the first phase has a half-life of approximately 2 hours (partition phase) in both young and elderly patients and the second phase (elimination phase) a half-life of approximately 10 hours in young subjects and approximately 14.5 hours in elderly subjects. ${ }^{1}$ Lormetazepam has been shown to be predominantly metabolized to the inactive glucuronide, ${ }^{2}$ with no evidence of accumulation of the active principle on repeat administration. ${ }^{3}$

The majority of patients receiving lormetazepam will, depending on their age and the aetiology of insomnia, respond well to doses ranging between 0.5 to $2.0 \mathrm{mg}$ daily, the highest dose being required only in the more resistant patients.

In this paper, we report the use of lormetazepam in a group of particularly disturbed psychiatric in-patients with severe insomnia requiring doses of lormetazepam of up to $6 \mathrm{mg}$ nightly. 


\section{Patients and methods}

Nineteen severely disturbed psychiatric in-patients who also suffered from particularly resistant insomnia were studied in an open evaluation for a mean period of 30 days ( \pm 18.5 days). The group was composed of 8 men and 11 women aged between 23 and 78 years (mean $43 \pm 14$ years). Details of the diagnoses are presented in Table I.

Table 1. Diagnosis of the patients entered in the study

\begin{tabular}{lc}
\hline Diagnosis & No. patients \\
\hline Depressive illness & 11 \\
Schizo-affective psychoses & 2 \\
Obsessional neuroses & 1 \\
Phobic neuroses & 1 \\
Chronic alcoholism & 1 \\
Refractory insomnia & 1 \\
Paranoid schizophrenia & 1 \\
Psychosomatic disorders & 1 \\
\hline Total & 19 \\
\hline
\end{tabular}

Lormetazepam was introduced at a dose of $2 \mathrm{mg}$ nightly and was increased by $1 \mathrm{mg}$ every 2 days until either the sleep disturbance was controlled or a maximum dose of $6 \mathrm{mg}$ nightly was reached. As the clinical symptoms improved, the dose of lormetazepam was gradually reduced. The maximum doses of lormetazepam administered were $4 \mathrm{mg}$ in 3 patients, $5 \mathrm{mg}$ in 8 patients and $6 \mathrm{mg}$ in 8 patients.

Patients were assessed clinically with regard to the efficacy and acceptability of the drug. A particular note was made of the presence or absence of 'hang-over' effects, assessed as tiredness on the day following treatment. In addition, any adverse effects were recorded.

A number of patients received concomitant medication, details of which are given in Table II.

\section{Results}

The mean maximum daily dose of lormetazepam administered was $5.26 \mathrm{mg}$ $( \pm 0.72 \mathrm{mg})$.

The subjective response to treatment was assessed as 'good' in 18 patients and 'fair' in the remaining patient. No 'hang-over' effects were recorded in 13 patients, and slight 'hang-over' effects in 5 patients. One patient was not assessed. In no patient was the 'hang-over' effect recorded as being severe. No side-effects due to administration of lormetazepam were reported.

\section{Discussion}

Although the patients studied were a highly selected group of severely disturbed psychiatric cases, the results clearly suggest that lormetazepam has a high thera- 
Table II. Concomitant medication received by patients

\begin{tabular}{ll}
\hline Drug & No. patients \\
\hline Amitriptyline & 2 \\
Clomipramine & 2 \\
Clonazepam & 1 \\
Disulfiram & 1 \\
Dothiepin & 2 \\
Fluspirilene & 1 \\
Haloperidol & 2 \\
Lithium & 1 \\
Lorazepam & 2 \\
Maprotiline & 1 \\
Nialamide & 2 \\
Nomifensine & 1 \\
Pimozide & 1 \\
Procyclidine & 2 \\
Propericiazine & 1 \\
Propranolol & 2 \\
Prothipendyl & 1 \\
Sulpiride & 3 \\
Tiapride & 2 \\
Zimelidine & 1 \\
\hline
\end{tabular}

peutic index in that response was assessed 'as good' in 18 of the 19 patients and as 'fair' in the remaining patient. At doses of up to 3 times the normal maximum recommended daily dose, no adverse effects were noted and in only 5 cases was a 'hang-over' effect reported. Of these 5,1 patient was receiving specific therapy which produced sedation and in the other 4 the effects were only reported as being mild. One other case could not be classified.

A further interesting point is the wide variety of psycho-active drugs listed in Table II which were given concomitantly, without any untoward drug interaction in any patient.

\section{Acknowledgement}

Our thanks are due to Miss B. Hanlon for her help in the preparation of this manuscript.

\section{References}

1. Hümpel, M., Hienweboer, B., Milius, W., Hanke, H., and Wendt, H., (1980). Radioimmunologic determinations in plasma and urine of young and elderly subjects: first-pass effect. Clin. Pharmacol. Ther, 28, 673-679.

2. Hümpel, M., Illi, V., Milius, W., Wendt, H., and Kurowski, M., (1979). Absorption, distribution, elimination and metabolism of lormetazepam-5-14C. Pharmacokinetics, 4, 237-243.

3. Hümpel, M., Stopelli, I., and Rainer, E., (1981). Repeated administration and transfer to newborns via breast milk. Eur. J. Clin. Pharmacol. Submitted for publication. 